\title{
MODELS FOR MULTIPLE ATTRIBUTE GROUP DECISION MAKING WITH 2-TUPLE LINGUISTIC ASSESSMENT INFORMATION
}

\author{
GUIWU WEI*, RUI LIN, XIAOFEI ZHAO, HONGJUN WANG \\ Department of Economics and Management, Chongqing University of Arts and Sciences \\ Yongchuan 402160, China \\ *Corresponding author,E-mail:weiguiwu@ 163.com
}

Received: 05-02-2009

Accepted: 27-11-2009

\begin{abstract}
The aim of this paper is to investigate the multiple attribute group decision making(MAGDM) problems with 2tuple linguistic assessment information, in which the information about attribute weights is incompletely known, and the attribute values take the form of linguistic assessment information. In order to get the weight vector of the attribute, we establish two optimization models based on the basic ideal of traditional TOPSIS, by which the attribute weights can be determined. For the special situations where the information about attribute weights is completely unknown, we establish some other optimization models. By solving these models, we get two simple and exact formulas, which can be used to determine the attribute weights. Then, based on the TOPSIS method, calculation steps for solving MAGDM problems with 2-tuple linguistic assessment information are given. The weighted distances between every alternative and 2-tuple linguistic positive ideal solution (TLPIS) and 2-tuple linguistic negative ideal solution (TLNIS) are calculated. Then, according to the weighted distances, the relative closeness degree to the TLPIS is calculated to rank all alternatives. These methods have exact characteristic in linguistic information processing. They avoided information distortion and losing which occur formerly in the linguistic information processing. Finally, some practical examples are used to illustrate the developed procedures.
\end{abstract}

Keywords: Group decision making; Linguistic assessment information; 2-tuple; TOPSIS

\section{Introduction}

Making decisions with linguistic information is a usual task faced by many decision makers [1], and thus, the use of a linguistic approach is necessary [2]. Many approaches have been proposed for aggregating information up to now [3-17, 24-32]. Particularly for the linguistic multiple attribute group decision making problems, in which the attribute weights and expert weights take the form of real numbers, and the preference values take the form of linguistic variables, an approach based on the LOWA and LHA operators is proposed [4]. For the same decision problem, an approach based on the LOWG and LHGA operators is proposed [5]; an approach based on the EIOWG operator is proposed [6]. The above methods compute with words directly. In 2000, Herrera F. [7] developed a 2-tuple linguistic model based on fuzzy linguistic representation model, which represents the linguistic information with a pair of values called 2-tuple, composed by a linguistic term and a number. 2-tuple linguistic model has exact characteristic in linguistic information processing. It avoided information distortion and losing which occur formerly in the linguistic information processing. In recent years, this method has been widely used in group decision making problems [9-17].

Technique for order performance by similarity to ideal solution (TOPSIS) [18] one of known classical MADM method, was first developed by Hwang and Yoon [19] for solving a MADM problem. TOPSIS, known as one of the most classical MADM methods, is based on the idea, that the chosen alternative should have the shortest distance from the positive ideal solution and on the other side the farthest distance of the 
negative ideal solution. In [11], Wang and Fan extended the TOPSIS to solve the group decision making problems with 2-tuple linguistic assessment information which both the attribute values and attribute weight take the form of linguistic information. In the process of MAGDM with linguistic assessment information, sometimes, the attribute values take the form of linguistic assessment information, and the information about attribute weights is incompletely known or completely unknown because of time pressure, lack of knowledge or data, and the expert's limited expertise about the problem domain. All of the above methods, however, will be unsuitable for dealing with such situations. Therefore, it is necessary to pay attention to this issue. The aim of this paper is to develop a new method for linguistic MAGDM problems with incomplete weight information based the traditional ideas of TOPSIS. In order to do so, the remainder of this paper is set out as follows. In the next section, we introduce some basic concepts and operational laws of 2-tuple linguistic variables. In Section 3 we develop some practical methods based on the traditional ideas of TOPSIS for linguistic group decision making problem with incomplete weight information, which is straightforward and has no loss of information. In Section 4, we give some illustrative examples to verify the developed approach and to demonstrate its feasibility and practicality. In Section 5 we conclude the paper and give some remarks.

\section{Preliminaries}

Let $S=\left\{s_{i} \mid i=0,1, \mathrm{~L}, t\right\}$ be a linguistic term set with odd cardinality. Any label, $s_{i}$ represents a possible value for a linguistic variable, and it should satisfy the following characteristics [7-8]:

(1) The set is ordered: $s_{i}>s_{j}$, if $i>j$; (2) Max operator: $\max \left(s_{i}, s_{j}\right)=s_{i}$, if $s_{i} \geq s_{j}$; (3) Min operator: $\min \left(s_{i}, s_{j}\right)=s_{i}$, if $s_{i} \leq s_{j}$. For example, $\mathrm{S}$ can be defined as $S=\left\{s_{0}=\right.$ extremely poor $(E P), s_{1}=$ very $\operatorname{poor}(V P)$, $s_{2}=\operatorname{poor}(P), s_{3}=\operatorname{medium}(M), s_{4}=\operatorname{good}(G)$, $\left.s_{5}=\operatorname{very} \operatorname{good}(V G), s_{6}=\operatorname{extremely} \operatorname{good}(E G)\right\}$

The 2-tuple fuzzy linguistic representation model represents the linguistic information by means of a 2tuple, $(s, a)$, where $s$ is a linguistic label and $a$ is a numerical value that represents the value of the symbolic translation [7-8].
Definition 1. Let $\beta$ be the result of an aggregation of the indices of a set of labels assessed in a linguistic term set $S$, i.e., the result of a symbolic aggregation operation. $\beta \in[0, t]$, being $t+1$ the cardinality of $S$. Let $i=\operatorname{round}(\beta)$ and $\alpha=\beta-i$ be two values, such that, $i \in[0, t]$ and $\alpha \in[-0.5,0.5)$ then $\alpha$ is called a Symbolic Translation [7-8].

From this concept, Herrera F. [7-8] developed a linguistic representation model which represents the linguistic information by means of 2-tuple $\left(s_{i}, \alpha_{i}\right)$, $s_{i} \in S$ and $\alpha_{i} \in[-0.5,0.5):$

- $s_{i}$ represents the linguistic label of the information;

- $\alpha_{i}$ is a numerical value expressing the value of the translation from the original result $\beta$ to the closest index label $i$, in the linguistic term $\operatorname{set}\left(s_{i} \in S\right)$, i.e., the symbolic translation.

This linguistic representation model defines a set of functions to make transformations between linguistic 2tuple and numerical values:

Definition 2. Let $S=\left\{s_{0}, s_{1}, \mathrm{~L}, s_{t}\right\}$ be a linguistic term set and $\beta \in[0, t]$ a value supporting the result of a symbolic aggregation operation, then, the 2-tuple that expresses the equivalent information to is obtained with the following function:

$$
\begin{gathered}
\Delta:[0, t] \rightarrow S \times[-0.5,0.5) \\
\Delta(\beta)=\left\{\begin{array}{l}
s_{i}, i=\operatorname{round}(\beta) \\
\alpha=\beta-i, \quad \alpha \in[-0.5,0.5)
\end{array}\right.
\end{gathered}
$$

where "round" is the usual rounding operation, $s_{i}$ has the closest index label to " $\beta$ " and " $\alpha$ " is the value of the symbolic translation [7-8].

Definition 3. Let $S=\left\{s_{0}, s_{1}, \mathrm{~L}, s_{t}\right\}$ be a linguistic term set and $\left(s_{i}, \alpha_{i}\right)$ be a 2-tuple. There is always a function $\Delta^{-1}$, such that, from a 2-tuple, it returns its equivalent numerical value $\beta \in[0, t] \subset R$ [7-8]

$$
\begin{aligned}
& \Delta^{-1}: S \times[-0.5,0.5) \rightarrow[0, t] \\
& \Delta^{-1}\left(s_{i}, \alpha\right)=i+\alpha=\beta
\end{aligned}
$$

From Definitions 2 and 3 , it is obvious that the conversion of a linguistic term into a linguistic 2-tuple 
consists of adding a value 0 as symbolic translation [78]:

$$
s_{i} \in S \Rightarrow\left(s_{i}, 0\right)
$$

Definition 4. Let $\left(s_{k}, a_{k}\right)$ and $\left(s_{l}, a_{l}\right)$ be two 2tuples, then [7-8]

If $k<l$ then $\left(s_{k}, a_{k}\right)$ is smaller than $\left(s_{l}, a_{l}\right)$

If $k=l$ then

a) if $a_{k}=a_{l}$, then $\left(s_{k}, a_{k}\right),\left(s_{l}, a_{l}\right)$ represents the same information

b) if $a_{k}<a_{l}$ then $\left(s_{k}, a_{k}\right)$ is smaller than $\left(s_{l}, a_{l}\right)$

c) if $a_{k}>a_{l}$ then $\left(s_{k}, a_{k}\right)$ is bigger than $\left(s_{l}, a_{l}\right)$

Definition 5. A 2-tuple negation operator:

$$
n e g\left(s_{i}, \alpha\right)=\Delta\left(t-\left(\Delta^{-1}\left(s_{i}, \alpha\right)\right)\right)
$$

where $t+1$ is the cardinality of $S$, $S=\left\{s_{0}, s_{1}, \mathrm{~L}, s_{t}\right\}[7-8]$.

Definition 6. Let $x=\left\{\left(r_{1}, a_{1}\right),\left(r_{2}, a_{2}\right), \mathrm{K},\left(r_{n}, a_{n}\right)\right\}$ be a set of 2-tuples, the 2-tuple arithmetic mean is computed as follows [7-8]

$$
(\bar{r}, \bar{a})=\Delta\left(\frac{1}{n} \sum_{j=1}^{n} \Delta^{-1}\left(r_{j}, a_{j}\right)\right), \bar{r} \in S, \bar{a} \in[-0.5,0.5)
$$

Definition 7. Let $x=\left\{\left(r_{1}, a_{1}\right),\left(r_{2}, a_{2}\right), \mathrm{K},\left(r_{n}, a_{n}\right)\right\}$ be a set of 2-tuples and $\omega=\left(\omega_{1}, \omega_{2}, \mathrm{~L}, \omega_{n}\right)^{T}$ be the weighting vector of 2-tuples $\left(r_{j}, a_{j}\right)$ $(j=1,2, \mathrm{~L}, n)$ and $\omega_{j} \in[0,1], j=1,2, \mathrm{~L}, n$, $\sum_{j=1}^{n} \omega_{j}=1$. The 2-tuple weighted average is [7-8]

$$
\begin{aligned}
& \left(r / 9 \mathrm{QW}=\varphi\left(\left(r_{1}, a_{1}\right),\left(r_{2}, a_{2}\right), \mathrm{K},\left(r_{n}, a_{n}\right)\right)\right.
\end{aligned}
$$

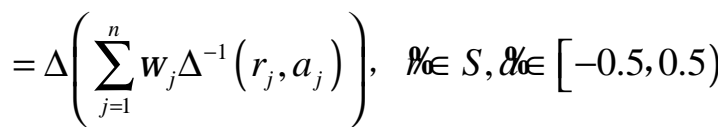

Definition 8. Let $\left(r_{i}, a_{i}\right)$ and $\left(r_{j}, a_{j}\right)$ be two 2-tuples, then we call [16]

$$
d\left(\left(r_{i}, a_{i}\right),\left(r_{j}, a_{j}\right)\right)=\Delta\left|\Delta^{-1}\left(r_{i}, a_{i}\right)-\Delta^{-1}\left(r_{j}, a_{j}\right)\right|
$$

the distance between $\left(r_{i}, a_{i}\right)$ and $\left(r_{j}, a_{j}\right)$.

\section{Models for multiple attribute group decision making (MAGDM) problems with 2-tuple linguistic assessment information}

The following assumptions or notations are used to represent the group decision making problems with incomplete weight information in linguistic setting:

Let $A=\left\{A_{1}, A_{2}, \mathrm{~L}, A_{m}\right\}$ be a discrete set of alternatives, $G=\left\{G_{1}, G_{2}, \mathrm{~L}, G_{n}\right\}$ be the set of attributes, $D=\left\{D_{1}, D_{2}, \mathrm{~L}, D_{t}\right\}$ be the set of decision makers. Suppose that $R_{k}=\left(r_{i j}^{(k)}\right)_{m \times n}$ is the group decision making matrix, where $r_{i j}^{(k)} \in S$ is a preference values, which take the form of linguistic variable, given by the decision maker $D_{k} \in D$, for the alternative $A_{i} \in A$ with respect to the attribute $G_{j} \in G$, $w=\left(w_{1}, w_{2}, \mathrm{~L}, w_{n}\right)$ is the weighting vector of the attributes $\quad G_{j}(j=1,2, \mathrm{~L}, n) \quad, \quad$ where $w_{j} \in[0,1], \sum_{j=1}^{n} w_{j}=1$.

For convenience of computation, we transform linguistic decision matrix $R_{k}=\left(r_{i j}^{(k)}\right)_{m \times n}$ into 2-tuple linguistic decision matrix $R_{k}=\left(r_{i j}^{(k)}, 0\right)_{m \times n}$, then utilize the decision information given in matrix $R_{k}$ to derive the collective overall 2-tuple linguistic decision matrix $R=\left(r_{i j}, a_{i j}\right)_{m \times n}$

$$
\begin{aligned}
\left(r_{i j}, a_{i j}\right) & =\Delta\left(\frac{1}{t} \sum_{k=1}^{t} \Delta^{-1}\left(r_{i j}, a_{i j}\right)\right) \\
i & =1,2, \mathrm{~L}, m, j=1,2, \mathrm{~L}, n .
\end{aligned}
$$

Definition 9. Let $\left(r_{j}^{+}, a_{j}^{+}\right)=\max _{i}\left\{\left(r_{i j}, a_{i j}\right)\right\}$, $j=1,2, \mathrm{~L}, n$, then

$$
\left(r^{+}, a^{+}\right)=\left(\left(r_{1}^{+}, a_{1}^{+}\right),\left(r_{2}^{+}, a_{2}^{+}\right), \mathrm{L},\left(r_{n}^{+}, a_{n}^{+}\right)\right)
$$

is called the 2-tuple linguistic positive ideal solution (TLPIS) $A^{+}$. 
Definition 10. Let $\left(r_{j}^{-}, a_{j}^{-}\right)=\min _{i}\left\{\left(r_{i j}, a_{i j}\right)\right\}$, $j=1,2, \mathrm{~L}, n$, then

$$
\left(r^{-}, a^{-}\right)=\left(\left(r_{1}^{-}, a_{1}^{-}\right),\left(r_{2}^{-}, a_{2}^{-}\right), \mathrm{L},\left(r_{n}^{-}, a_{n}^{-}\right)\right)
$$

is called the 2-tuple linguistic negative ideal solution (TLNIS) $A^{-}$.

For the convenience of depiction, based on the 2tuple linguistic decision matrix, we denote the alternative $A_{i}(i=1,2, \mathrm{~L}, m)$ as:

$$
\begin{array}{r}
A_{i}=\left(\left(r_{i 1}, a_{i 1}\right),\left(r_{i 2}, a_{i 2}\right), \mathrm{L},\left(r_{i n}, a_{i n}\right)\right), \\
i=1,2, \mathrm{~L}, m .
\end{array}
$$

where $\left(r_{i j}, a_{i j}\right)$ indicate the attribute values of $A_{i}$ corresponding to the attribute $G_{j}(j=1,2, \mathrm{~L}, n)$.

Definition 11. The weighted distances between $A_{i}$ and $A^{+}$is defined as follows:

$$
\begin{aligned}
& d\left(A_{i}, A^{+}\right)=\left(\xi_{i}^{+}, \eta_{i}^{+}\right) \\
& =\Delta\left(\sum_{j=1}^{n}\left|\Delta^{-1}\left(r_{i j}, a_{i j}\right)-\Delta^{-1}\left(r_{j}^{+}, a_{j}^{+}\right)\right| w_{j}\right)
\end{aligned}
$$

Definition 12. The weighted distances between $A_{i}$ and $A^{-}$is defined as follows:

$$
\begin{aligned}
& d\left(A_{i}, A^{-}\right)=\left(\xi_{i}^{-}, \eta_{i}^{-}\right) \\
& =\Delta\left(\sum_{j=1}^{n}\left|\Delta^{-1}\left(r_{i j}, a_{i j}\right)-\Delta^{-1}\left(r_{j}^{-}, a_{j}^{-}\right)\right| w_{j}\right)
\end{aligned}
$$

Definition 13. The relative closeness of the alternative $A_{i}$ with respect to $A^{+}$is defined as

$$
\begin{aligned}
& c\left(A_{i}, A^{+}\right)=\left(\xi_{i}, \eta_{i}\right) \\
& =\Delta\left(\frac{\Delta^{-1}\left(\xi_{i}^{-}, \eta_{i}^{-}\right)}{\Delta^{-1}\left(\xi_{i}^{+}, \eta_{i}^{+}\right)+\Delta^{-1}\left(\xi_{i}^{-}, \eta_{i}^{-}\right)}\right)
\end{aligned}
$$

The relative closeness (16) can be used to rank all alternatives. The larger the relative closeness $c\left(A_{i}, A^{+}\right)$is, the better the alternative $A_{i}$ is.

If the information about the attribute weights is completely known, then we can determine the ranking of all alternatives and select the best one(s) in accordance with the relative closeness $c\left(A_{i}, A^{+}\right)(i=1,2, \mathrm{~L}, m) . \quad$ In the following, we apply TOPSIS method to solve the 2tuple linguistic MAGDM with completely known weight information.

Example 1. Let us suppose there is an investment company, which wants to invest a sum of money in the best option (adapted from [2]). There is a panel with five possible alternatives to invest the money: (1) $\mathrm{A}_{1}$ is a car company; (2) $A_{2}$ is a food company; (3) $A_{3}$ is a computer company; (4) $\mathrm{A}_{4}$ is an arms company; (5) $\mathrm{A}_{5}$ is a TV company. The investment company must take a decision according to the following four attributes: $1 \mathrm{G}_{1}$ is the risk analysis; (2) $\mathrm{G}_{2}$ is the growth analysis; (3) $\mathrm{G}_{3}$ is the social-political impact analysis; (4) $\mathrm{G}_{4}$ is the environmental impact analysis. The five possible alternatives $A_{i}(i=1,2, \mathrm{~L}, 5)$ are to be evaluated using the linguistic term set $S$ by the three decision makers under the above four attributes, and construct the decision matrices $R_{k}=\left(r_{i j}^{(k)}\right)_{5 \times 4}(k=1,2,3)$ as follows:

$$
\begin{aligned}
& \begin{array}{llll}
G_{1} & G_{2} & G_{3} & G_{4}
\end{array}
\end{aligned}
$$

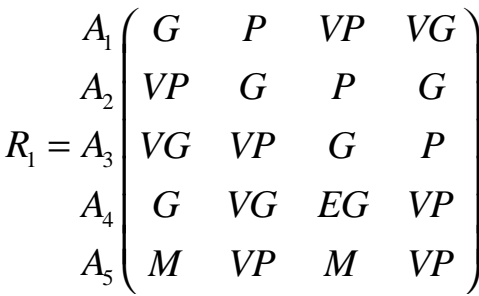




$$
\begin{aligned}
& \begin{array}{llll}
G_{1} & G_{2} & G_{3} & G_{4}
\end{array}
\end{aligned}
$$

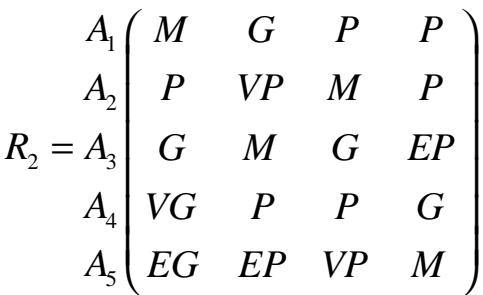

$$
\begin{aligned}
& \begin{array}{llll}
G_{1} & G_{2} & G_{3} & G_{4}
\end{array}
\end{aligned}
$$

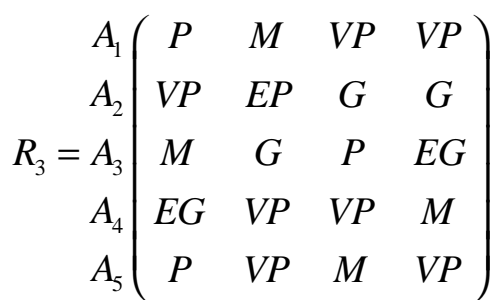

Firstly, we transform linguistic decision matrix $R_{k}=\left(r_{i j}^{(k)}\right)_{m \times n}$ into 2-tuple linguistic decision matrix $R_{k}=\left(r_{i j}^{(k)}, 0\right)_{m \times n}$ as follows

$$
\begin{aligned}
R_{1} & =\left(\begin{array}{cccc}
(G, 0) & (P, 0) & (V P, 0) & (V G, 0) \\
(V P, 0) & (G, 0) & (P, 0) & (G, 0) \\
(V G, 0) & (V P, 0) & (G, 0) & (P, 0) \\
(G, 0) & (V G, 0) & (E G, 0) & (V P, 0) \\
(M, 0) & (V P, 0) & (M, 0) & (V P, 0)
\end{array}\right) \\
R_{2} & =\left(\begin{array}{cccc}
(M, 0) & (G, 0) & (P, 0) & (P, 0) \\
(P, 0) & (V P, 0) & (M, 0) & (P, 0) \\
(G, 0) & (M, 0) & (G, 0) & (E P, 0) \\
(V G, 0) & (P, 0) & (P, 0) & (G, 0) \\
(E G, 0) & (E P, 0) & (V P, 0) & (M, 0)
\end{array}\right) \\
R_{3}= & \left(\begin{array}{cccc}
(P, 0) & (M, 0) & (V P, 0) & (V P, 0) \\
(V P, 0) & (E P, 0) & (G, 0) & (G, 0) \\
(M, 0) & (G, 0) & (P, 0) & (E G, 0) \\
(E G, 0) & (V P, 0) & (V P, 0) & (M, 0) \\
(P, 0) & (V P, 0) & (M, 0) & (V P, 0)
\end{array}\right)
\end{aligned}
$$

Then, we utilize Eq. (10) to derive the collective overall 2-tuple linguistic decision matrix $R=\left(r_{i j}, a_{i j}\right)_{m \times n}$ as follows:

$$
R=\left(\begin{array}{cccc}
(M, 0) & (M, 0) & (V P, 0.33) & (M,-0.33) \\
(V P, 0.33) & (P,-0.33) & (M, 0) & (M, 0.33) \\
(G, 0) & (M,-0.33) & (M, 0.33) & (M,-0.33) \\
(V G, 0) & (M,-0.33) & (M, 0) & (M,-0.33) \\
(G,-0.33) & (V P,-0.33) & (P, 0.33) & (P,-0.33)
\end{array}\right)
$$

If the information about the attribute weights is completely known as follows:

$$
w=(0.1000,0.2000,0.3200,0.3800)
$$

Then, we utilize the approach developed to get the most desirable alternative(s).

Step 1. Defining the TLPIS and TLNIS as $\left(r^{+}, a^{+}\right)=((V G, 0),(M, 0),(M, 0.33),(M, 0.33))^{T}$ $\left(r^{-}, a^{-}\right)=((V P, 0.33),(V P,-0.33),(V P, 0.33),(P,-0.33))^{T}$

Step 2. Calculating the distances of each alternative from TLPIS and TLNIS by Eq. (14-15)

$$
\begin{aligned}
& \left(\xi_{1}^{+}, \eta_{1}^{+}\right)=(V P, 0.093),\left(\xi_{2}^{+}, \eta_{2}^{+}\right)=(V P,-0.260) \\
& \left(\xi_{3}^{+}, \eta_{3}^{+}\right)=(E P, 0.420),\left(\xi_{4}^{+}, \eta_{4}^{+}\right)=(E P, 0.427) \\
& \left(\xi_{5}^{+}, \eta_{5}^{+}\right)=(P,-0.447),\left(\xi_{1}^{-}, \eta_{1}^{-}\right)=(P, 0.013) \\
& \left(\xi_{2}^{-}, \eta_{2}^{-}\right)=(V P, 0.367),\left(\xi_{3}^{-}, \eta_{3}^{-}\right)=(P,-0.313) \\
& \left(\xi_{4}^{-}, \eta_{4}^{-}\right)=(P,-0.320),\left(\xi_{5}^{-}, \eta_{5}^{-}\right)=(V P,-0.447)
\end{aligned}
$$

Step 3. Calculating the relative closeness degree of each alternative from TLPIS by Eq. (16)

$$
\begin{aligned}
& \left(\xi_{1}, \eta_{1}\right)=(E P, 0.481),\left(\xi_{2}, \eta_{2}\right)=(V P,-0.351) \\
& \left(\xi_{3}, \eta_{3}\right)=(V P,-0.199),\left(\xi_{4}, \eta_{4}\right)=(V P,-0.203) \\
& \left(\xi_{5}, \eta_{5}\right)=(E P, 0.263)
\end{aligned}
$$

Step 4. Ranking all the alternatives $A_{i}(i=1,2, \mathrm{~L}, 5)$ in accordance with the relative closeness degree $\left(\xi_{i}, \eta_{i}\right): A_{3} \mathrm{f} A_{4} \mathrm{f} A_{2} \mathrm{f} A_{1} \mathrm{f} A_{5}$, and thus the most desirable alternative is $A_{3}$.

In the following, we shall apply TOPSIS method to solve the 2-tuple linguistic MAGDM with incompletely known weight information. $H$ is the set of the known weight information, which can be constructed by the following forms[20-23], for $i \neq j$ : Form 1. A weak 
ranking: $w_{i} \geq w_{j} \quad ; \quad$ Form 2. A strict ranking: $w_{i}-w_{j} \geq \alpha_{i}, \alpha_{i}>0$; Form 3. A ranking of differences: $w_{i}-w_{j} \geq w_{k}-w_{l}$, for $j \neq k \neq l$; Form 4. A ranking with multiples: $w_{i} \geq \beta_{i} w_{j}, 0 \leq \beta_{i} \leq 1$;

Form 5. An interval form: $\alpha_{i} \leq w_{i} \leq \alpha_{i}+\varepsilon_{i}$, $0 \leq \alpha_{i}<\alpha_{i}+\varepsilon_{i} \leq 1$

The basic principle of the TOPSIS method is that the chosen alternative should have the "shortest distance" from the positive ideal solution and the "farthest distance" from the negative ideal solution. Obviously, for the weight vector given, the smaller $d\left(A_{i}, A^{+}\right)$and the larger $d\left(A_{i}, A^{-}\right)$is, the better alternative $A_{i}$ is. But the information about attribute weights is incompletely known. So, in order to get the $d\left(A_{i}, A^{+}\right)$ and $d\left(A_{i}, A^{-}\right)$, firstly, we must calculate the weight information. So, we can establish the following multiple objective optimization models (M.1) and (M.2) to calculate the weight information:

$\left\{\begin{array}{l}(\mathrm{M} .1) \min \left(\xi_{i}^{+}, \eta_{i}^{+}\right)=\Delta\left(\sum_{j=1}^{n}\left|\Delta^{-1}\left(r_{i j}, a_{i j}\right)-\Delta^{-1}\left(r_{j}^{+}, a_{j}^{+}\right)\right| w_{j}\right) \\ \text { subject to: } w \in H, i=1,2, \mathrm{~L}, m .\end{array}\right.$ $\left\{\begin{array}{l}(\mathrm{M} .2) \max \left(\xi_{i}^{-}, \eta_{i}^{-}\right)=\Delta\left(\sum_{j=1}^{n}\left|\Delta^{-1}\left(r_{i j}, a_{i j}\right)-\Delta^{-1}\left(r_{j}^{-}, a_{j}^{-}\right)\right| w_{j}\right) \\ \text { subject to }: w \in H, i=1,2, \mathrm{~L}, m .\end{array}\right.$

Since each alternative is non-inferior, so there exists no preference relation on the all the alternatives. Then, we may aggregate the above multiple objective optimization models with equal weights into the following multiple objective optimization models (M.3) and (M.4): $\left\{\begin{aligned} &(\mathrm{M} .3) \max (\xi, \eta)=\Delta\left(\sum_{i=1}^{m}\left(\Delta^{-1}\left(\xi_{i}^{+}, \eta_{i}^{+}\right)\right)\right) \\ &=\Delta\left(\sum_{i=1}^{m} \sum_{j=1}^{n}\left(\left|\Delta^{-1}\left(r_{i j}, a_{i j}\right)-\Delta^{-1}\left(r_{j}^{+}, a_{j}^{+}\right)\right| w_{j}\right)\right.\end{aligned}\right.$

subject to $: w \in H$

$\left\{\begin{aligned}(\text { M.4) } & \max (\xi, \eta)=\Delta\left(\sum_{i=1}^{m}\left(\Delta^{-1}\left(\xi_{i}^{-}, \eta_{i}^{-}\right)\right)\right) \\ = & \Delta\left(\sum_{i=1}^{m} \sum_{j=1}^{n}\left(\left|\Delta^{-1}\left(r_{i j}, a_{i j}\right)-\Delta^{-1}\left(r_{j}^{-}, a_{j}^{-}\right)\right| w_{j}\right)\right.\end{aligned}\right.$

subject to $: w \in H$

According to $\Delta^{-1}$ function, multiple objective optimization models (M.3) and (M.4) can be transformed into the single objective optimization models (M.5) and (M.6):

$$
\left\{\begin{aligned}
\text { (M.5) } & \min \Delta^{-1}(\xi, \eta)=\sum_{i=1}^{m}\left(\Delta^{-1}\left(\xi_{i}^{+}, \eta_{i}^{+}\right)\right) \\
= & \sum_{i=1}^{m} \sum_{j=1}^{n}\left(\left|\Delta^{-1}\left(r_{i j}, a_{i j}\right)-\Delta^{-1}\left(r_{j}^{+}, a_{j}^{+}\right)\right|\right) w_{j}
\end{aligned}\right.
$$

subject to $: w \in H$

$$
\left\{\begin{array}{l}
\text { (M.6) } \max \Delta^{-1}(\xi, \eta)=\sum_{i=1}^{m}\left(\Delta^{-1}\left(\xi_{i}^{-}, \eta_{i}^{-}\right)\right) \\
=\sum_{i=1}^{m} \sum_{j=1}^{n}\left(\left|\Delta^{-1}\left(r_{i j}, a_{i j}\right)-\Delta^{-1}\left(r_{j}^{-}, a_{j}^{-}\right)\right|\right) w_{j}
\end{array}\right.
$$

subject to $: w \in H$

By solving the models (M.5) and (M.6), we get the optimal solution $w^{+}=\left(w_{1}^{+}, w_{2}^{+}, \mathrm{L}, w_{n}^{+}\right) \quad$ and $w^{-}=\left(w_{1}^{-}, w_{2}^{-}, \mathrm{L}, w_{n}^{-}\right)$, which can be used as the weight vector of attributes. Then, we can get $\left(\xi_{i}^{+}, \eta_{i}^{+}\right)$ 
and $\left(\xi_{i}^{-}, \eta_{i}^{-}\right)$by Equations (14-15), respectively. Then we utilize (16) to derive the relative closeness $c\left(A_{i}, A^{+}\right)(i=1,2, \mathrm{~L}, m)$, by which we can rank all the alternatives $A_{i}(i=1,2, \mathrm{~L}, m)$ and select the best one(s).

If the information about attribute weights is completely unknown, we can construct the following single objective optimization models:

$$
\begin{aligned}
& \left\{\begin{array}{l}
\text { (M.7) } \min \Delta^{-1}(\xi, \eta)=\sum_{i=1}^{m}\left(\Delta^{-1}\left(\xi_{i}^{+}, \eta_{i}^{+}\right)\right)^{2} \\
=\sum_{i=1}^{m} \sum_{j=1}^{n}\left(\left|\Delta^{-1}\left(r_{i j}, a_{i j}\right)-\Delta^{-1}\left(r_{j}^{+}, a_{j}^{+}\right)\right|\right)^{2} w_{j}^{2}
\end{array}\right. \\
& \text { subject to }: \sum_{j=1}^{n} w_{j}=1, w_{j} \geq 0, j=1,2, \mathrm{~L}, n . \\
& \quad=\sum_{i=1}^{m} \sum_{j=1}^{n}\left(\mid \Delta^{-1}\left(r_{i j}, a_{i j}\right)-\Delta^{-1}\left(r_{j}^{-}, a_{j}^{-}\right)\right)^{2} w_{j}^{2} \\
& \text { (M.8) } \max \Delta^{-1}(\xi, \eta)=\sum_{i=1}^{m}\left(\Delta^{-1}\left(\xi_{i}^{-}, \eta_{i}^{-}\right)\right)^{2} \\
& \text { subject to }: \sum_{j=1}^{n} w_{j}=1, w_{j} \geq 0, j=1,2, \mathrm{~L}, n .
\end{aligned}
$$

To solve the models (M.7) and (M.8), we get two simple and exact formula for determining the attribute weights as follows:

$$
\begin{gathered}
w_{j}^{+}=\frac{\left(\sum_{i=1}^{m}\left|\Delta^{-1}\left(r_{i j}, a_{i j}\right)-\Delta^{-1}\left(r_{j}^{+}, a_{j}^{+}\right)\right|^{2}\right)^{-1}}{\sum_{j=1}^{n}\left(\sum_{i=1}^{m}\left|\Delta^{-1}\left(r_{i j}, a_{i j}\right)-\Delta^{-1}\left(r_{j}^{+}, a_{j}^{+}\right)\right|^{2}\right)^{-1}} \\
j=1,2, \mathrm{~L}, n . \text { (17) }
\end{gathered}
$$

$$
w_{j}^{-}=\frac{\left(\sum_{i=1}^{m}\left|\Delta^{-1}\left(r_{i j}, a_{i j}\right)-\Delta^{-1}\left(r_{j}^{-}, a_{j}^{-}\right)\right|^{2}\right)^{-1}}{\sum_{j=1}^{n}\left(\sum_{i=1}^{m}\left|\Delta^{-1}\left(r_{i j}, a_{i j}\right)-\Delta^{-1}\left(r_{j}^{-}, a_{j}^{-}\right)\right|^{2}\right.}
$$

which can be used as the weight vector of attributes. Obviously, $w_{j} \geq 0$, for all $j$. Then, we can get $d\left(A_{i}, A^{+}\right)(i=1, \mathrm{~L}, m) \quad$ and $d\left(A_{i}, A^{-}\right)(i=1, \mathrm{~L}, m)$ by Equations (14-15) respectively. Then we utilize (16) to derive the relative closeness $c\left(A_{i}, A^{+}\right)(i=1,2, \mathrm{~L}, m)$, by which we can rank all the alternatives $A_{i}(i=1,2, \mathrm{~L}, m)$ and select the best one(s).

Example 2. For the MAGDM problem considered in Example 1, suppose that the information about the attribute weights is partly known as follows:

$$
\begin{aligned}
& H=\left\{0.05 \leq w_{1} \leq 0.10,0.18 \leq w_{2} \leq 0.23,\right. \\
& 0.25 \leq w_{3} \leq 0.32,0.35 \leq w_{4} \leq 0.47 \\
& \left.w_{j} \in[0,1], j=1,2,3,4, \sum_{j=1}^{4} w_{j}=1\right\}
\end{aligned}
$$

Then by models (M.5) and (M.6), we can establish the following two single-objective programming models:

$\left\{\begin{array}{l}\min \Delta^{-1}(\xi, \eta)=8.00 w_{1}+4.33 w_{2}+3.67 w_{3}+3.67 w_{4} \\ \text { Subject to }: w \in H\end{array}\right.$
$\left\{\begin{array}{l}\max \Delta^{-1}(\xi, \eta)=10.33 w_{1}+7.33 w_{2}+6.33 w_{3}+4.67 w_{4} \\ \text { Subject to }: w \in H\end{array}\right.$

To solve these models, we get the weight vector of attributes:

$$
\begin{aligned}
& w^{+}=(0.0500,0.1800,0.3125,0.4575) \\
& w^{-}=(0.0716,0.1800,0.2784,0.4700)
\end{aligned}
$$


by Eq. $(14,15)$, we get

$$
\begin{aligned}
& \left(\xi_{1}^{+}, \eta_{1}^{+}\right)=(V P, 0.030),\left(\xi_{2}^{+}, \eta_{2}^{+}\right)=(V P,-0.472) \\
& \left(\xi_{3}^{+}, \eta_{3}^{+}\right)=(E P, 0.415),\left(\xi_{4}^{+}, \eta_{4}^{+}\right)=(E P, 0.469) \\
& \left(\xi_{5}^{+}, \eta_{5}^{+}\right)=(P, 0 .-438),\left(\xi_{1}^{-}, \eta_{1}^{-}\right)=(V P, 0.009) \\
& \left(\xi_{2}^{-}, \eta_{2}^{-}\right)=(V P, 0.427),\left(\xi_{3}^{-}, \eta_{3}^{-}\right)=(P,-0.422) \\
& \left(\xi_{4}^{-}, \eta_{4}^{-}\right)=(P,-0.443),\left(\xi_{5}^{-}, \eta_{5}^{-}\right)=(E P, 0.445)
\end{aligned}
$$

By Eq.(16), we have

$$
\begin{aligned}
& \quad \begin{array}{l}
\left(\xi_{1}, \eta_{1}\right)=(E P, 0.495),\left(\xi_{2}, \eta_{2}\right)=(V P,-0.270) \\
\left(\xi_{3}, \eta_{3}\right)=(V P,-0.208),\left(\xi_{4}, \eta_{4}\right)=(V P,-0.232) \\
\left(\xi_{5}, \eta_{5}\right)=(E P, 0.222) \\
\text { Since } \\
c\left(A_{3}, A^{+}\right) \mathrm{f} c\left(A_{4}, A^{+}\right) \mathrm{f} c\left(A_{2}, A^{+}\right) \mathrm{f} c\left(A_{1}, A^{+}\right) \mathrm{f} c\left(A_{5}, A^{+}\right)
\end{array}
\end{aligned}
$$

then

$A_{3} \mathrm{f} A_{4} \mathrm{f} A_{2} \mathrm{f} A_{1} \mathrm{f} A_{5}$, Hence, the most desirable alternative is $A_{3}$.

If the information about attribute weights is completely unknown, then by (17-18), we have

$$
\begin{aligned}
& w^{+}=(0.0800,0.2172,0.3096,0.3933) \\
& w^{-}=(0.0935,0.1862,0.2548,0.4655)
\end{aligned}
$$

by Eq. $(14,15)$, we get

$$
\begin{aligned}
& \left(\xi_{1}^{+}, \eta_{1}^{+}\right)=(V P, 0.041),\left(\xi_{2}^{+}, \eta_{2}^{+}\right)=(V P,-0.314) \\
& \left(\xi_{3}^{+}, \eta_{3}^{+}\right)=(E P, 0.415),\left(\xi_{4}^{+}, \eta_{4}^{+}\right)=(E P, 0.438) \\
& \left(\xi_{5}^{+}, \eta_{5}^{+}\right)=(P,-0.422),\left(\xi_{1}^{-}, \eta_{1}^{-}\right)=(V P, 0.056) \\
& \left(\xi_{2}^{-}, \eta_{2}^{-}\right)=(V P, 0.387),\left(\xi_{3}^{-}, \eta_{3}^{-}\right)=(P,-0.403) \\
& \left(\xi_{4}^{-}, \eta_{4}^{-}\right)=(P,-0.395),\left(\xi_{5}^{-}, \eta_{5}^{-}\right)=(E P, 0.473)
\end{aligned}
$$

By Eq.(16), we have

$$
\begin{aligned}
& \left(\xi_{1}, \eta_{1}\right)=(V P,-0.497),\left(\xi_{2}, \eta_{2}\right)=(V P,-0.331) \\
& \left(\xi_{3}, \eta_{3}\right)=(V P,-0.206),\left(\xi_{4}, \eta_{4}\right)=(V P,-0.214) \\
& \left(\xi_{5}, \eta_{5}\right)=(E P, 0.231)
\end{aligned}
$$

Since

$$
c\left(A_{3}, A^{+}\right) \text {f } c\left(A_{4}, A^{+}\right) \text {f } c\left(A_{2}, A^{+}\right) \text {f } c\left(A_{1}, A^{+}\right) \text {f } c\left(A_{5}, A^{+}\right)
$$

then
$A_{3} \mathrm{f} A_{4} \mathrm{f} A_{2} \mathrm{f} A_{1} \mathrm{f} A_{5}$, Hence, the most desirable alternative is $A_{3}$.

Besides, the advantage of the approach presented in this paper is clear using a computing with word representation model, 2-tuple linguistic representation that allows us to aggregate linguistic information without losing it.

\section{Conclusion}

In this paper, we have investigated the problem of 2tuple linguistic multiple attribute group decision-making with incompletely known attribute weight information. A modified TOPSIS analysis method is proposed. In order to get the attribute weight, we establish the multiple objective optimization models based on the basic ideal of the traditional TOPSIS. Then, by linear equal weighted method, the multiple objective optimization models can be transformed into two singleobjective programming model. By solving the singleobjective programming models, we can get the attribute weight information. For the special situations where the information about attribute weights is completely unknown, we establish some other optimization models. By solving these models, we get two simple and exact formula, which can be used to determine the attribute weights. Then, the weighted distances between every alternative and TLPIS and TLNIS are calculated. Then, according to the weighted distances, the relative closeness degree to the TLPIS is calculated to rank all alternatives. They avoided information distortion and losing which occur formerly in the linguistic information processing. Finally, an illustrative example is given. These methods have exact characteristic in linguistic information processing. By comparing with the TOPSIS method proposed in literature [11], the approach presented in this paper proves to be effective to solve the MAGDM problems with 2-tuple linguistic assessment information, in which the information about attribute weights is incompletely known, and the attribute values take the form of linguistic assessment information. In the future, we shall extend TOPSIS method to solve the 2-tuple linguistic multiple attribute group decision-making with unbalanced linguistic term sets.

\section{Acknowledgment}

The author is very grateful to the editor and the anonymous referees for their insightful and constructive comments and suggestions, which have been very helpful in improving the paper. The work was supported by the Humanities and Social Sciences Foundation of 
Ministry of Education of the People's Republic of China (No.09XJA630010)

\section{References}

[1] Z. S. Xu, Uncertain Multiple Attribute Decision Making: Methods and Applications, Tsinghua University Press, Beijing, 2004.

[2] M., Delgado F. Herrera, E. Herrera-Viedma and L. Martinez, Combining Numerical and Linguistic Information in Group Decision Making", Information Sciences 107(1998) 177-194.

[3] R. Degani and G. Bortolan, The problem of linguistic approximation in clinical decision making, International Journal of Approximate Reasoning 2(2) (1998)143-162.

[4] Z. S. Xu, A note on linguistic hybrid arithmetic averaging operator in multiple attribute group decision making with linguistic information, Group Decision and Negotiation 15(6) (2006) 593-604.

[5] Z. S. Xu, A method based on linguistic aggregation operators for group decision making with linguistic preference relations, Information Sciences 166(1) (2004)19-30.

[6] Z. S. Xu, Extended IOWG operator and its use in group decision making based on multiplicative linguistic preference relations, American Journal of Applied Sciences 2(3) (2005) 633-643.

[7] F.Herrera and L. Martínez, A 2-tuple fuzzy linguistic representation model for computing with words, IEEE Transactions on Fuzzy Systems 8 (2000) 746-752.

[8] F. Herrera and L. Martínez, A model based on linguistic 2-tuples for dealing with multigranular hierarchical linguistic contexts in multi-expert decision-making, IEEE Transactions on Systems, Man, and Cybernetics 31 (2001) 227-234.

[9] X. R. Wang, Z. P. Fan, A method for group decision making problems with different forms of preference information, Journal of Northeastern University (Natural Science) 24(2) (2003)178-181.

[10] F. Herrera, E. Herrera-Viedma, J. Verdegay, A linguistic decision process in group decision making, Group Decision and Negotiation 5(1) (1996) 165-176.

[11] X. R. Wang, Z. P. Fan, Method for group decision making based on 2-tuple linguistic information processing, Journal of Management Science in China 6(5) (2003) 1-5.

[12] F. Wei, C. A. Liu, S. Y. Liu, A method for group decision making with linguistic information based on uncertain information processing, Operational Research and management Science 15(3) (2006) 31-35.
[13] Y. P. Jiang, Z. P. Fan, An approach to group decision-making problems based on 2-tuple linguistic symbol operation, Systems Engineering and Electronics 25(11) (2003) 1373-1376.

[14] H. Y. Li, Z. P. Fan, Multi-criteria group decision making method based on 2-tuple linguistic information processing, Journal of Northeastern University (Natural Science) 24(5) 495-498.

[15] H. Y. Li, Z. P. Fan, Comprehensive multi-attribute group evaluation with linguistic assessment information, Journal of Northeastern University (Natural Science) 26(7) (2005)703-706.

[16] X. W. Liao, Y. Li, G. M. Dong, A multi-attribute group decision-making approach dealing with linguistic assessment information, System Engineering-Theory \& Practice 26(9) (2006) 90-98.

[17] Y. P. Jiang, Z. P. Fan, Property analysis of the aggregation operators for 2-tuple linguistic information, Control and Decision 18(6) 754-757.

[18] Y.J. Lai, T.Y. Liu, C.L. Hwang, TOPSIS for MOD”, European Journal of Operational Research 76(3) (1994) 486-500.

[19] C.L. Hwang, K. Yoon, Multiple Attribute Decision Making Methods and Applications, Springer, Berlin Heidelberg, 1981.

[20] P. S. Park, S. H. Kim, W. C. Yoon, Establishing strict dominance between alternatives with special type of incomplete information, European Journal of Operational Research 96(1996) 398-406

[21] K.S. Park and S.H. Kim, Tools for interactive multi-attribute decision making with incompletely identified information, European Journal of Operational Research 98 (1997) 111-123.

[22] S.H. Kim, S.H. Choi and J.K. Kim, An interactive procedure for multiple attribute group decision making with incomplete information: range-based approach, European Journal of Operational Research 118 (1999) 139-152.

[23] S.H. Kim and B.S. Ahn, Interactive group decision making procedure under incomplete information, European Journal of Operational Research 116 (1999) 498-507.

[24]F. Herrera, E. Herrera-Viedma, L. Martínez, A fuzzy linguistic methodology to deal with unbalanced linguistic term sets. IEEE Transactions on Fuzzy Systems 16(2) (2008) 354-370.

[28] G.W. Wei and R. Lin, Method of grey relational analysis for multiple attribute group decision making based on 2-tuple linguistic information, Journal of Systems Engineering and Electronics 30(9) (2008) 1686-1689.

[26] G.W. Wei, 2-tuple linguistic multiple attribute group decision making with incomplete attribute weight information, Journal of Systems Engineering and Electronics 30(2) (2008) 273-277. 
[27]G.W. Wei, Uncertain linguistic hybrid geometric mean operator and its Application to group decision making under uncertain linguistic environment, International Journal of Uncertainty, Fuzziness, Knowledge-Based Systems 17(2) (2009) 251-267.

[28] X.B. Li, D. Ruan, J. Liu and Y. Xu, A linguisticvalued weighted aggregation operator to multiple attribute group decision making with quantative and qualitative information, International Journal of Computational Intelligence Systems 1(3) (2008) 274-284.

[29] J. Ma, D. Ruan, Y. Xu and G. Zhang, A fuzzy-set approach to treat determinacy and consistency of linguistic terms in multi-criteria decision making,
International Journal of Approximate Reasoning, 44(2)(2007)165-181.

[30] L. Martínez, D. Ruan, F. Herrera, E. HerreraViedma, P.P. Wang, Linguistic decision making: Tools and applications, Information Sciences 179(14) (2009) 2297-2298.

[31] L. Martínez, J. Liu, D. Ruan, J.B. Yang, Dealing with heterogeneous information in engineering evaluation processes, Information Sciences 177(7) (2007)1533-1542.

[32] X.W. Liao, Y Li and B. Lu, A model for selecting an ERP system based on linguistic information processing, Information Systems 32(7) (2007) 1005-1017. 